\title{
The Pain Disability Questionnaire: a reliability and validity study
}

\author{
Patrícia Cantu Moreira Giordano ${ }^{1}$ \\ Neusa Maria Costa Alexandre ${ }^{2}$ \\ Roberta Cunha Matheus Rodrigues ${ }^{2}$ \\ Marina Zambon Orpinelli Coluci ${ }^{3}$
}

\begin{abstract}
The goal of this study was to translate and adapt The Pain Disability Questionnaire (PDQ) to Brazilian Portuguese, as well as to assess its psychometric properties and practicability. The following methodological steps were followed: translation, synthesis, back-translation, expert committee assessment and pre-test. The psychometric properties were assessed through the application of a questionnaire to 119 patients with chronic musculoskeletal disorders. The results indicated the reliability of the instrument, with a Cronbach's alpha coefficient of 0.86 , and high stability in the test-retest. A moderate correlation was found between the PDQ scores and the numerical pain scale. Negative correlations were found between the Spitzer Quality of Life Index and the functional condition, psychosocial component and total PDQ score. Construct validity demonstrated significant difference in PDQ scores between symptomatic and asymptomatic individuals. The PDQ revealed fast application and easy understanding. The results indicated a successful cultural adaptation and reliable psychometric properties.

Descriptors: Validity of Tests; Reproducibility of Results; Measures; Disabled Persons; Musculoskeletal Diseases.
\end{abstract}

\footnotetext{
1 Physical Therapist, M.Sc. in Nursing, Departamento de Enfermagem, Faculdade de Ciências Médicas, Universidade Estadual de Campinas, SP, Brazil. E-mail: paticmg@fcm.unicamp.br.

2 RN, Free Lecturer, Associate Professor, Departamento de Enfermagem, Faculdade de Ciências Médicas, Universidade Estadual de Campinas, SP, Brazil. E-mail: Neusa - neusalex@fcm.unicamp.br, Roberta - robertar@fcm.unicamp.br.

${ }^{3}$ Physical Therapist, Doctoral Student in Health Sciences, Departamento de Enfermagem, Faculdade de Ciências Médicas, Universidade Estadual de Campinas, SP, Brazil. E-mail: marinazo@fcm.unicamp.br.
}

Corresponding Author:

Patrícia Cantu Moreira Giordano

Rua Tessália Vieira de Camargo, 126

Caixa Postal 6111

Cidade Universitária "Zeferino Vaz"

CEP: 13083-887, Campinas, SP, Brasil.

E-mail: paticmg@fcm.unicamp.br 


\title{
The Pain Disability Questionnaire: um estudo de confiabilidade e validade
}

O objetivo deste estudo foi traduzir e adaptar The Pain Disability Questionnaire (PDQ) para o português do Brasil, avaliar suas propriedades psicométricas e praticabilidade. Os seguintes passos metodológicos foram seguidos: tradução, síntese, retrotradução, avaliação por comitê de especialistas e pré-teste. As propriedades psicométricas foram avaliadas pela aplicação do questionário a 119 pacientes com lesões musculoesqueléticas crônicas. Os resultados indicaram a confiabilidade do instrumento com o coeficiente alfa de Cronbach de 0,86, e alta estabilidade na aplicação do teste-reteste. Uma correlação moderada foi encontrada entre os escores do PDQ e a escala numérica de dor. Correlações negativas foram encontradas entre o Spitzer Quality of Life Index e a condição funcional, componente psicossocial e escore total do PDQ. A validade de construto demonstrou diferença significativa nos escores do PDQ entre indivíduos sintomáticos e assintomáticos. O PDQ mostrou aplicação rápida e fácil entendimento. Os resultados indicaram sucesso na adaptação cultural e propriedades psicométricas confiáveis.

Descritores: Validade dos Testes; Reprodutibilidade dos Testes; Medidas; Pessoa com Incapacidade; Doenças Musculosqueléticas.

\section{The Pain Disability Questionnaire: estudio de confiabilidad y validación}

\begin{abstract}
El objetivo de este estudio fue traducir y adaptar el Cuestionario The Pain Disability Questionnaire (PDQ) para el portugués de Brasil, evaluando sus propiedades psicométricas y la usabilidad. Fueron seguidos los siguientes pasos metodológicos: traducción, síntesis, retrotraducción, evaluación por un comité de expertos y realización de una prueba piloto. Las propiedades psicométricas fueron evaluadas por la aplicación del cuestionario en 119 pacientes con lesiones musculares. Los resultados indican la confiabilidad del instrumento con el coeficiente alfa de Cronbach de 0,86, y alta estabilidad en la prueba piloto. Una correlación moderada se encontró entre las puntuaciones de la PDQ y la escala numérica del dolor. Correlaciones negativas fueron observadas entre el Spitzer Quality of Life Index y la condición funcional, el componente psicosocial, y la puntuación total de la PDQ. La validez del constructo demostró una diferencia significativa en las puntuaciones del PDQ entre sujetos sintomáticos y asintomáticos. EI PDQ demostró ser rápido y comprensible. Los resultados indicaron una exitosa adaptación cultural y propiedades psicométricas confiables.
\end{abstract}

Descriptores: Validez de las Pruebas; Reproducibilidad de Resultados; Medidas; Personas con Discapacidad; Enfermedades Musculoesqueléticas.

\section{Introduction}

Musculoskeletal disorders are a major public health problem in developed countries ${ }^{(1)}$. They are common in workers and the general population, and their origin is

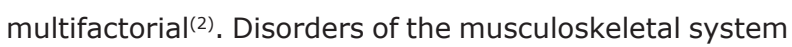
have also attracted researchers' attention concerning health- and work-related issues, due to the incurred costs and impact on quality of life. This impact includes functional loss, activity limitations, reduced quality of life, disability, decreased work productivity and direct medical $\operatorname{costs}^{(3)}$. They thus have a great impact on the population, due to their high prevalence and morbidity, entailing great potential for disability.

Organizations and researchers concerned with issues relating to health and work have been studying measures to assess disability in subjects with musculoskeletal symptoms. Questionnaires and scales have been considered useful to evaluate the various aspects of disability. The cultural adaptation of 
questionnaires already validated in another language has been widely recommended, because it facilitates information exchange among scientific communities.

The Pain Disability Questionnaire (PDQ) aims to measure disability. It is derived from clinical research that indicates that biopsychosocial factors interact mutually during the development of pain and disability. The Pain Disability Questionnaire (PDQ) addresses both physical and psychosocial aspects, which can be measured through independent scores. The PDQ can also be analyzed based on the total score(4).

Since the PDQ has demonstrated reliable psychometric properties and there is a lack of translation into Brazilian Portuguese language, we decided to realize its cross-cultural adaptation.

Thus, the objective of this study was to translate and adapt The Pain Disability Questionnaire into Brazilian Portuguese, and to assess its psychometric properties.

\section{Methods}

\section{Cross-Cultural Adaptation Process}

The following methodological steps were followed to guarantee the quality of the instrument: initial translation, synthesis, back-translation, review committee, pretest, back-translation and evaluation of psychometric properties ${ }^{(5-6)}$.

Initial Translation and Synthesis

The original version of The Pain Disability Questionnaire (PDQ) was translated into Portuguese by two bilingual translators whose native language was Brazilian-Portuguese. One translator was aware of the objectives of the study and the other not. The two translated versions were compared by the investigators and a mediator (a professional translator). Discrepancies were identified and a consensus was reached on a common version ${ }^{(6)}$.

\section{Back-translation}

The Brazilian-Portuguese version was translated back into English by two translators whose native language was English. They were neither affiliated with the research team or institution, nor had they participated in the first stage.

\section{Review Committee}

All translated and back-translated versions were submitted to a committee of bilingual judges, composed of two doctors, one a specialist in pain and the other with disability experience; a nurse with experience in the area of workplace disabilities; a nurse with methodological expertise; two physical therapists with experience in musculoskeletal disorders; and a professional translator. Initially, they received an instrument constructed specifically for the evaluation process, with instructions to be considered on the semantic, idiomatic, cultural and conceptual equivalences ${ }^{(6)}$.

For quantitative analysis, the agreement percentage score was applied by dividing the number of judges who agreed with the item by the total number of judges(7). Items that reached an agreement level higher than or equal to $90 \%$ would be considered appropriate(7). Subsequently, a meeting was held with all experts to conduct a qualitative analysis(7). In this stage, the judges evaluated the instrument and elements requiring revision were revised through joint discussion and agreement.

\section{Pretesting}

To evaluate the equivalence of the questionnaire within the Brazilian cultural environment, a pretest was carried out with a sample of 30 patients with chronic musculoskeletal disorders who attended a physical therapy clinic $^{(6)}$.

\section{Evaluation of psychometric properties}

Reliability

Reliability was obtained through internal consistency and stability (test-retest). The internal consistency was verified though Cronbach's alpha coefficient. The stability (test-retest) was evaluated by applying the questionnaire to the same group of patients on two different occasions, at a 48-hour interval, under the same conditions.

Validity

Validity was analyzed using the correlation between (i) $P D Q$ scores and numerical pain scale, and (ii) the Spitzer Quality of Life Index (QLI) scores.

The validity of known-groups was verified by applying the questionnaire to two groups with distinct characteristics: a group with musculoskeletal disorders, and one without these disorders.

Usability

The usability of an instrument refers to the practical aspects the researcher should consider, including time 
constraints and ease of administration. The usability questionnaire aimed to measure the time spent and the easiness to fill out the PDQ.

\section{Subjects and setting}

The data were collected at a Physical therapy outpatient clinic. Following referral and medical diagnosis, patients with chronic musculoskeletal disease receive care at this clinic, located in the Department of Orthopedics. Chronic pain was defined as that lasting more than 12 weeks $^{(8)}$. Patients were excluded if they were unable to communicate effectively, and / or were illiterate.

For the evaluation of the validity of known-groups, a convenience sample of 76 employees of the same hospital participated, without musculoskeletal disorders. This group consisted of those who (i) stated that they had no difficulty to perform their work, (ii) had no musculoskeletal symptoms or other disabling diseases, and (iii) had no reported history of musculoskeletal disorders or leave of absence from occupational activities.

\section{Data collection}

The data were collected before the physiotherapy sessions took place. The full protocol received the approval of the University's Institutional Review Board. All patients who participated in this study were asked to provide written consent prior to enrollment. Subject characterization was conducted, using a form with the following data: date, age, gender, education, employment, diagnosis and duration of pain.

The subjects were asked to complete a selfreported instrument package: Numerical Pain Scale, Spitzer Quality of Life Index (QLI) and the Pain Disability Questionnaire. Then, during a second physical therapy session, 48 hours after having filled out these questionnaires, the subjects responded only the PDQ and the usability questionnaire, under the same conditions.

The Numerical Pain Scale was used to evaluate the intensity of pain, with scores from 0 to 10 , with zero meaning "no pain" and ten "the worst pain imaginable"(9). The scale is easy to use and understand for patients with less schooling and demonstrated satisfactory reliability ${ }^{(9)}$.

The Spitzer Quality of Life Index (QLI) is a generic instrument for evaluating quality of life. It consists of five domains: involvement in occupational and domestic activities; activities of daily life; perception of the patient's own health; support from family and friends and perspectives on one's life. This instrument had been previously translated and adapted for the Brazilian population, specifically for use with patients manifesting chronic back pain. The Brazilian version showed satisfactory reliability and validity ${ }^{(10)}$.

The Pain Disability Questionnaire (PDQ) is an instrument for measuring disability caused by pain. It consist of 15 items, divided into two domains: one measuring the Functional Condition, consisting of nine items $(1,2,3,4,5,6,7,12,13)$; and the other measuring the Psychosocial Component, consisting of six items $(8,9,10,11,14,15)$. The Functional Condition has a maximum score of 90 points, and the psychosocial component a maximum score of 60 . The total score of the PDQ, ranging from 0 to 150 , is the total of the scores on the two components. The following classification is used to examine the score: mild/moderate (0-70); severe (71-100); and extreme (101-150)(11). Reliability of the original instrument, assessed through the testretest method, was 0.94 to 0.98 . The analysis of internal consistency showed a Cronbach's Alpha coefficient of $0.96^{(4)}$

The usability of the PDQ was assessed using an instrument which queried the time taken to complete the instrument and the extent to which the instructions and questions were easy to understand. The instrument consisted of three items and used a five-item Likert scale(12).

\section{Statistical analyses}

The data were entered into the Excel software program and examined under the guidance of the University's Statistical Office, using The SAS System for Windows (version 8.02) and SPSS for Windows (version 10.0).

First, descriptive data were analyzed regarding socio-demographic characteristics, domains and total score on the PDQ, Spitzer (QLI), Numeric Pain Scale and usability questionnaire. The Cronbach's alpha coefficient was checked, considering a satisfactory evidence of internal consistency if $>0.70^{(13)}$. Analysis of test-retest reliability were made with the Intraclass Correlation Coefficient (ICC), which evidences stability of the instrument if $\geq 0.75^{(14)}$.

Validity was verified using the Spearman Correlation Coefficient, correlating the PDQ with the Numerical Pain Scale and with Spitzer (QLI), and considering values close to 0.30 as satisfactory, between 0.30 and 0.50 as moderate, and over 0.50 as strong(15). The MannWhitney test was chosen to assess the validity using 
the known-groups technique. The significance level for statistical tests was $5 \%$.

\section{Results}

\section{Cross-cultural adaptation process}

The process of cultural adaptation was completed without any problem. During evaluation by the expert committee of specialists, questions 1,10 and the layout of the questionnaire obtained an agreement rate of $100 \%$. The other questions passed by simple changes, like as inversion or substitution of a synonym, in order to facilitate understanding. The committee proposed more substantial changes for the title, the instructions and questions $3,5,6$.

In the pretest, the mean age of the patient sample was $44.6( \pm 8.40)$ years. The average PDQ score was 75.7, indicating severe disability ${ }^{(11)}$. Upon completing the instrument, patients were asked about difficulties to understand questions or specific words. On question eight, $5 \%$ of respondents reported difficulty to understand the word income. This term was replaced by monthly income. This concluded the cultural adaptation process, resulting in the Brazilian version of the instrument.

\section{Description of the sample}

A total of 119 subjects with chronic musculoskeletal disorders participated in the study, with a mean age of 46.9 years $( \pm 9.2)$. The majority of the subjects $(80.6 \%)$ was female. The most common education level was primary $(53.7 \%)$. Duration of pain was on average 3.7 years $( \pm 3.96)$, with higher incidence between one and five years. Low back pain was the most frequent disorder. Table 1 shows the scores obtained on the questionnaires and scales used.

Table 1 - Scores of questionnaires: The Numerical Pain Scale; Spitzer (QLI) and PDQ

\begin{tabular}{|c|c|c|c|c|}
\hline Instruments (range of scores) & Mean ( $\pm S D)$ & Median & Minimum value & Maximum value \\
\hline Numerical Pain Scale $(0-10)$ & $8.4( \pm 1.4)$ & 8 & 0 & 10 \\
\hline Spitzer (QLI) (0-10) & $5.5( \pm 2.2)$ & 6 & 1.0 & 10 \\
\hline Total PDQ (0-150) & $89.6( \pm 29.2)$ & 92 & 0.0 & 150 \\
\hline Functional Condition (0-90) & $54.8( \pm 19.4)$ & 56 & 16 & 90 \\
\hline Psychosocial Component (0-60) & $34.5( \pm 12.9)$ & 33 & 8 & 60 \\
\hline
\end{tabular}

\section{Psychometric properties}

Reliability

Internal consistency of the instrument, indicated by Cronbach's alpha, corresponded to 0.86 for total PDQ scores, 0.83 for the Functional Component and 0.70 for the Psychosocial Component. High stability was found when using a test-retest design, with ICC of 0.95 for the total score, 0.94 for the Functional Condition and 0.95 for the Psychosocial Component.

Validity

Moderately significant correlations were found between the Numerical Pain Scale scores and the total and both dimensions of the PDQ: Functional Condition $(r=0.33)$, Psychosocial Component $(r=0.38)$ and total score of the PDQ $(r=0.36)$. A significant negative correlation was found between the Spitzer score (QLI) and the dimensions Functional Condition ( $r=-0.63)$, Psychosocial Component $(r=-0.69)$, and total score $(r=-$ 0.70 ) of the PDQ.
A significant difference was found when comparing the subject groups with and without musculoskeletal disorders to assess the known-groups validity. The average age of the group without musculoskeletal disorders was 44.7 years ( \pm 8.9 ) (Table 2 ).

Table 2 - Comparison between mean scores from groups with $(\mathrm{N}=119)$ and without $(\mathrm{N}=76)$ musculoskeletal disorders

\begin{tabular}{lccc}
\hline \multicolumn{1}{c}{ Item } & $\begin{array}{c}\text { Subjects with disorders } \\
\text { musculoskeletal } \\
\text { Mean }( \pm \text { SD) }\end{array}$ & $\begin{array}{c}\text { Subjects without } \\
\text { disorders } \\
\text { Mean }( \pm \text { SD) }\end{array}$ & P* \\
\hline Total PDQ & $89.6( \pm 29.2)$ & $15.9( \pm 3.4)$ & 0.0001 \\
$\begin{array}{l}\text { Functional } \\
\text { Condition }\end{array}$ & $55.1( \pm 19.4)$ & $9.5( \pm 2.0)$ & 0.0001 \\
$\begin{array}{l}\text { Psychosocial } \\
\text { Component }\end{array}$ & $34.5( \pm 12.4)$ & $6.3( \pm 1.4)$ & 0.0001 \\
\hline
\end{tabular}

* Mann-Whitney Test

Usability

The mean time of participants' response to the PDQ instrument was 6 minutes and 20 seconds ( $\pm 2.9 \mathrm{~min}$.) (Table 3). 
Table 3 - Results of the application of the questionnaire on the usability of assessment instruments $(\mathrm{N}=119)$

\begin{tabular}{|c|c|c|c|c|c|}
\hline Questions & $\begin{array}{c}\text { TD } \\
\text { n (\%) }\end{array}$ & $\begin{array}{c}\text { PD } \\
\text { n (\%) }\end{array}$ & $\begin{array}{l}\text { HNO } \\
\text { n (\%) }\end{array}$ & $\begin{array}{c}\text { PA } \\
\text { n (\%) }\end{array}$ & $\begin{array}{c}\text { TA } \\
\mathrm{n}(\%)\end{array}$ \\
\hline I found the questionnaire instructions easy to understand & 0 & $7(5.8)$ & $14(11.7)$ & $33(27.7)$ & $65(54.6)$ \\
\hline I found the questionnaire questions easy to understand & 0 & $4(3.3)$ & $14(11.7)$ & $34(28.7)$ & $67(56.3)$ \\
\hline I found it easy to fill out the questionnaire answers & 0 & $6(5.0)$ & $14(11.7)$ & $35(39.4)$ & $64(53.7)$ \\
\hline
\end{tabular}

$\mathrm{TD}=$ totally disagree, $\mathrm{PD}=$ partially disagree, $\mathrm{NO}=$ no opinion, $\mathrm{PA}=$ partially agree, $\mathrm{TA}=$ totally agree.

\section{Discussion}

The objective of the present study was to translate and adapt "The Pain Disability Questionnaire" into Brazilian Portuguese and assess its psychometric properties. The process of cultural adaptation followed all the steps suggested in international literature and the entire process was carried out as planned.

Subject characteristics corroborate with those presented in the literature, indicating an average age of over 40 years $^{(16)}$. We also found a predominance of females, similarly with another study ${ }^{(17)}$. The study population was composed of individuals with low education, with $53.7 \%$ having attended only primary education. A previous study appointed educational level as an individual risk factor for the development of low back pain(18).

Patients received a clinical diagnosis, and the musculoskeletal disorder with greater incidence was low back pain. The duration of pain was on average 3.7 years $( \pm 3.9)$, characteristic of a population with chronic symptoms.

The analysis of descriptive results revealed an average score of 8.4 on pain intensity. The Spitzer (QLI) result was 5.5, reflecting moderate quality of life ${ }^{(10)}$. Studies have confirmed the negative interference of musculoskeletal symptoms in various dimensions of quality of life ${ }^{(19)}$. Disability caused by pain showed an average PDQ Total score of 89.6, with Functional Condition subscore of 54.8 and Psychosocial Component subscore of 34.5. Considering this result, the sample revealed a severe impairment with reduction in Functional and Psychosocial dimensions ${ }^{(11)}$. The literature describes the impact of psychosocial factors in subjects with chronic pain and the importance of examining these factors in the clinical evaluation(20).

Regarding the reliability of the PDQ, this study found high internal consistency(13). Validation of the original PDQ found a Cronbach's alpha of $0.96^{(4)}$. In this study, test-retest reliability of the PDQ resulted in an ICC of 0.95. Recall that the instrument was applied in the initial evaluation of physiotherapy and then reapplied before the start of treatment, so there was no interference in the pain-development process. There is no consensus in the literature regarding the most effective interval for application of the test-retest, due to the influence of natural fluctuation of pain associated with the memory effect.

With respect to the original version, a coefficient of reliability (test-retest) of 0.94 was found in assessing the stability of PDQ Total in 230 subjects with chronic musculoskeletal disorders It is noteworthy that a similar result was reached in this study and this result confirms the evidence of stability of the PDQ ${ }^{(14)}$.

The correlation of score of the PDQ with Numerical Pain Scale was statistically significant and of moderate magnitude $(r=0.36)^{(15)}$. In validating the PDQ, a previous study correlated disability with the intensity of pain using an analog scale of pain, obtaining a value of $r=0.44^{(4)}$.

A previous study found a correlation of 0.62 between the intensity of pain and disability in patients with low back pain ${ }^{(21)}$. The authors noted that many factors could determine the degree of disability, such as those related to work. The literature has shown that to study the relationship between intensity of pain and disability, a number of variables should be considered, e.g., frequency and location of pain, presence of depression, beliefs about pain, etc. ${ }^{(20)}$. Disability caused by pain involves the interaction between physical, psychological and social factors.

As previously hypothesized, a statistically significant negative correlation was found between quality of life, as measured by the Spitzer questionnaire (QLI), and disability: a value of $r=-0.70$ for the total PQD, $r=-0.63$ for the Functional Condition and $r=-0.69$ for the Psychosocial Component. In assessing validity, the authors correlated the PDQ scores with the mental and physical domains of the SF-36. The authors found a correlation of 0.48 for mental component and 0.40 for the physical aspects( ${ }^{(4)}$. The PDQ showed a correlation with two different instruments used to assess quality of life, showing interference regarding several dimensions that verify the quality of life in patients with chronic musculoskeletal pain. 
The SF-36 was also used in another study in order to assess the impact of musculoskeletal disorders on quality of life, with greater impact on physical, emotional and social factors ${ }^{(22)}$. Another study describes quality of life as an important indicator of disability, characteristic of musculoskeletal disorders ${ }^{(23)}$. Indeed, the literature has shown that musculoskeletal symptoms interfere in a negative way with the quality of life of individuals living with these disorders(24).

Statistically significant differences were found between subjects with and without musculoskeletal disorders in evaluating the validity of known-groups. This suggests that the instrument can discriminate between subjects who have difficulty in carrying out various activities of daily living.

A further assessment, the usability questionnaire, was implemented in order to verify time spent and ease of application of the PDQ. The PDQ proved to be rapid administration, with a duration of 6 minutes, and easy to understand. The usability questionnaire may be useful to researchers concerned with the quality of their datacollection instrument ${ }^{(12)}$.

It should be noted that the PDQ has been adjusted to patients with chronic musculoskeletal disorders. Future studies should be conducting using individuals with other diseases.

\section{Conclusion}

The process of cultural adaptation of The Pain Disability Questionnaire - PDQ was successful, following internationally accepted methodological standards. The PDQ will be useful in research and clinical practice in the evaluation of patients with chronic musculoskeletal disorders.

\section{References}

1. Bergman S. Public health perspective- how to improve the musculoskeletal health of the population. Best Pract Res Clin Rheumatol. 2007;1(21):191-207.

2. Andersen $\mathrm{CH}$, Haahr JP. Frost P. Risk factors for more severe regional musculoskeletal symptoms: A two-year prospective study of a general working population. Arthritis Rheum. 2007;56(4):1255-364.

3. Ricci JA, Stewart WF, Chee E, Leotta C, Foley $\mathrm{K}$, Hochberg MC. Back pain exacerbations and lost productive time costs in United States workers. Spine. 2006;31(26):3052-60.
4. Anagnostis C, Gatchel RJ, Mayer TG. The pain disability questionnaire: a new psychometrically sound measure for chronic musculoskeletal disorders. Spine. 2004;29(20):2290-302.

5. Alexandre NMC, Guirardello EB. Adaptación cultural de instrumentos utilizados em salud ocupacional. Rev Panam Salud Publica. 2002;11(2):109-11.

6. Beaton D, Bombardier C, Guillemin F, Ferraz MB. Recommendations for the process of crosscultural adaptation of self-report measures. Spine. 2000;25(24):3186-91.

7. Alexandre NMC, Coluci MZO. Validade de conteúdo nos processos de construção e adaptação de instrumentos de medida. Cienc Saúde Coletiva. 2011;16(7):12-22.

8. Nordin M, Alexandre NMC, Campelo M. Measures for low back pain: a proposal for clinical use. Rev. LatinoAm. Enfermagem. 2003;11(2):152-5.

9. Gallasch $\mathrm{CH}$, Alexandre NMC. The measurement of musculoskeletal pain intensity: a comparison of four methods. Rev Gaucha Enferm. 2007;28(2):260-5.

10. Toledo RMR, Alexandre NMC, Rodrigues RCM. Psychometric evaluation of a Brasilian Portuguese version of the Spitzer Quality of Life Index in patients with low back pain. Rev. Latino-Am. Enfermagem. 2008;16(6):943-50.

11. Gatchel RJ, Mayer TG, Theodore BR. The pain disability questionnaire: relationship to one-year functional and psychosocial rehabilitation outcomes. J Occup Rehabil. 2006;1(16):75-94.

12. Coluci MZO, Alexandre NMC. Development of a questionnaire to evaluate the usability of assessment instruments. Rev Enferm UERJ. 2009;17(3):378-82.

13. DeVon HA, Block ME, Moyle-Wright P, Ernst DM, Hayden SJ, Lazzara DJ, et al. A psychometric toolbox for testing validity and reliability. J Nurs Scholarsch. 2007;39(2):155-64.

14. Terwee CB, Bot SDM, Boer MR, van der Windt DAWM, Knol DL, Dekker J, et al. Quality criteria were proposed for measurement properties of health status questionnaires. J Clin Epidemiol. 2007;60(1):34-42.

15. Ajzen I, Fishbein M. Understanding attitudes and predicting social behavior. New Jersey: Prentice-Hall; 1998.

16. Carleton RN, Abrams MP, Kachur SS, Asmundson GSG. A comparison of anatomical pain sites from a tertiary care sample: Evidence of disconnect between functional and perceived disability specific to lower back pain. Eur J Pain. 2010;14:410-7. 
17. Wijnhoven HAH, de Vet HCW, Picavet HSJ. Sex differences in consequences of musculoskeletal pain. Spine. 2007;32(12):1360-7.

18. Dionne C, Von Korff M, Koepsell TD, Deyo R, Barlow W, Checkpway H. Formal education and back pain: a review. J Epidemiol Communty Health. 2001;55:455-68. 19. Kovacs FM, Abraira V, Zamora J, Teresa Gil del Real M, Llobera J, Fernández $C$, et al. Correlation between pain, disability, and quality of life in patients with common low back pain. Spine. 2004;29(2):206-10.

20. Geisser EM, Robinson ME, Miller QL, Geertzen JHB, Dijkstra PU. Psychosocial factors and functional capacity evaluation among persons with chronic pain. J Occup Rehabil. 2003;4(13):259-76.

21. Grönblad $M$, Hupli $M$, Wennerstran $P$, Järvinen $E$, Lukinmaa $A$, Kouri JP, et al. Intercorrelation and testretest reability of the Pain Disability Index (PDI) and the Oswestry Disability Questionnaire (ODQ) and their correlation with Pain Intensity in low back pain patients. Clin J Pain. 1993;9:189-95.

22. Roux $\mathrm{CH}$, Guillemin F, Boini S, Longuetaud F, Arnault $\mathrm{N}$, Hercberg $\mathrm{S}$, et al. Impact of musculoskeletal disorders on quality of life: an inception cohort study. Ann Rheum Dis. $2005 ; 64: 606-1$.

23. Picavet HSJ, Hoeymans N. Health related quality of life in multiple musculoskeletal diseases: SF-36 and EQ5D in the DMC3 study. Ann Rheum Dis. 2004;63:723-9. 24. Yilmaz F, Sahin F, Ergoz E, Deniz E, Ercalik C, Yucel SD, Kuran B. Quality of life assessments with SF 36 in different musculoskeletal diseases. Clin Rheumatol. 2008;27:327-32. 